\title{
RELATIONS BETWEEN THE MICROSCALE RIVERBED MORPHOLOGY AND THE MACROZOOBENTHOS - IMPLICATIONS FOR THE ECOLOGICAL QUALITY ASSESSMENT AND THE DEFINITION OF REFERENCE CONDITIONS
}

\author{
MICHAEL GROLL \\ Department of Geography, Philipps-Universität Marburg, Germany
}

\begin{abstract}
European rivers have been constantly affected by anthropogenic impairments throughout the course of human history. Since 2000 the European Water Framework Directive (WFD) accelerated the process of recognizing and reclaiming rivers as valuable ecosystems, and the restoration of river stretches has become an essential tool for the improvement of watercourses in Central Europe. These restoration measures need to be complemented by in-depth scientific evaluations to ensure the cost-effectiveness of the extensive rehabilitation programme. In this study, two restored river stretches in the middle reaches of the River Lahn (Germany) were analysed in great detail between 2006 and 2008, with a special focus on the macrozoobenthos (MZB) and the small-scale riverbed morphology. The MZB is one of four quality components used for the evaluation of rivers within the WFD and despite the more than a century-long history of limnological research focused on benthic invertebrates, the central question of which morphological processes and structures have to be improved in order to reach the 'good ecological status' is still largely unanswered as detailed research of the faunistic-morphological connections on the micro scale (choriotopes) is still few and far between. Both areas - the MZB and the hydromorphology - were covered in an extensive field work programme. The riverbed was mapped using the TRiSHa method ('Typology of Riverbed Structures and Habitats') and a detailed survey of the MZB (165 samples) was carried out in accordance with the PERLODES method. Both data sets were analysed for their spatial diversity and for their interrelations. Furthermore the 'ecological status' was assessed in accordance with the WFD. This evaluation revealed gaps in the German river typology and the assessment method that should ignite a broader scientific discussion about the benefits of nationwide unified evaluation methods versus regionalized approaches.
\end{abstract}

Keywords: ecological quality assessment, European water framework directive, Germany, Lahn, macrozoobenthos, microhabitats, monitoring, river restoration.

\section{INTRODUCTION}

The intensive use of the European rivers during the last hundreds of years has led to profound changes in the physicochemical properties, river morphology and the aquatic fauna $[1,2]$. As a result, the quality of the German freshwater resources deteriorated so much during the 20th century that many rivers could no longer fulfil their multi-purpose functions within the ecological and economic systems. This and several incidents which gained considerable media coverage (like the Sandoz hazard in 1986) led to a programmatic water quality improvement of the German rivers during the last 50 years. Because of enforced water quality regulations and wastewater treatment processes, the biological state of most German rivers increased to a 'good' state [3]. However, the hydromorphology did not improve so that the structural degradation remains and $60 \%$ of all German surface water bodies are considered to morphologically heavily modified [3]. Rectifying these deficits is the biggest unsolved challenge for the German rivers and streams to date [4]. The most important step towards this goal was the approval of the European Water Framework Directive (WFD) with its central aim of restoring all European surface water bodies to a good chemical and ecological status until 2027 [5]. One of 
the four ecological quality parameters used for the assessment of this status is the macrozoobenthos (MZB) - the larger invertebrate animal species living on/in the riverbed substrates. These species have been studied for more than a century and are used for decades as indicators for the pollution and the morphological degradation of freshwater ecosystems [1, 6-8]. The implementation of the WFD requires a detailed knowledge about the morphological and ecological deficits which forms the basis for extensive restoration programmes. But this knowledge of how to select suitable measures in a cost-effective way is mostly theoretical and insufficient $[9,10]$. There are hardly any detailed data about the relations between the morphological properties of rivers and the colonization patterns of the aquatic fauna and evaluations of implemented restoration measures are still rather the exception than the norm [2, 11-14]. Considering the large investment needed for reaching the aims of the WFD (between 18 and $50 \mathrm{Bln} . €$ in Germany alone [2]), closing this knowledge gap is paramount for the successful improvement of the freshwater resources. To analyse these important relations between the riverbed morphology and the aquatic fauna in revitalized river stretches is the central premise of the research presented here [15].

\section{RESEARCH AREA}

The river selected for this research was the Lahn near Marburg, a large river of the lower mountain region (type 9.2 [16]) in Hesse (Germany) with - at that point - a catchment size of $1,666.2 \mathrm{~km}^{2}$ and an average discharge of $16.7 \mathrm{~m}^{3} / \mathrm{s}$. Two restored river section and one control section of the Lahn were selected as the research areas (Fig. 1). These three areas represent different characteristics of the river Lahn. The first area ('Auf der Weide') had been restored in 2002 and is located in the inner city of Marburg, downstream of a weir. It features a high flow variability and in parts a shallow riverbed. The research area 'Cappeler Fischerwiese' is located $6 \mathrm{~km}$ downstream of the first area and $1 \mathrm{~km}$ upstream of a weir, resulting in a lower flow velocity and a deeper riverbed. This area had been restored in two steps in 1997 and in 2005. A control area ('Gisselberger Straße') is located between the first two river stretches, downstream of the Marburg gauge. It has not yet been restored and is characterized by a straight river course, a shallow riverbed and a high flow velocity. A total of ten study sites were selected within the three research areas in order to cover a wide range of different characteristics - two side channel and two main channel sites in each restored area and two sites in the control stretch (Fig. 1). The river banks in all three research areas are $1.5 \mathrm{~m}$ high and fortified by rubble. The restoration measures followed the concept of a braided river which supposedly was the natural state of the Lahn in this region, though a thorough examination of historical maps (ranging back to 1715) could not find any evidence for natural river branches [15]. The restoration measures were implemented following the passive dynamic river development approach which supports processes caused by the natural discharge dynamic while being very inexpensive. This makes this approach the preferred tool for small-scale river restoration projects in Germany, but without a proper post-restoration evaluation, the effectiveness of this approach remains uncertain.

\section{METHODS}

The field work for this study consisted of two major steps: the detailed mapping of the riverbed morphology and the sampling of the macrozoobenthos. The riverbed substrates, organic structures (like coarse and fine particulate organic matter or macrophytes), the water depth and the flow velocity were mapped using the TRiSHa method ('Typology of Riverbed Structures and Habitats') [15, 17]. This mapping of 1,069 plots (each measuring $1 \mathrm{~m}^{2}$ ) was repeated 

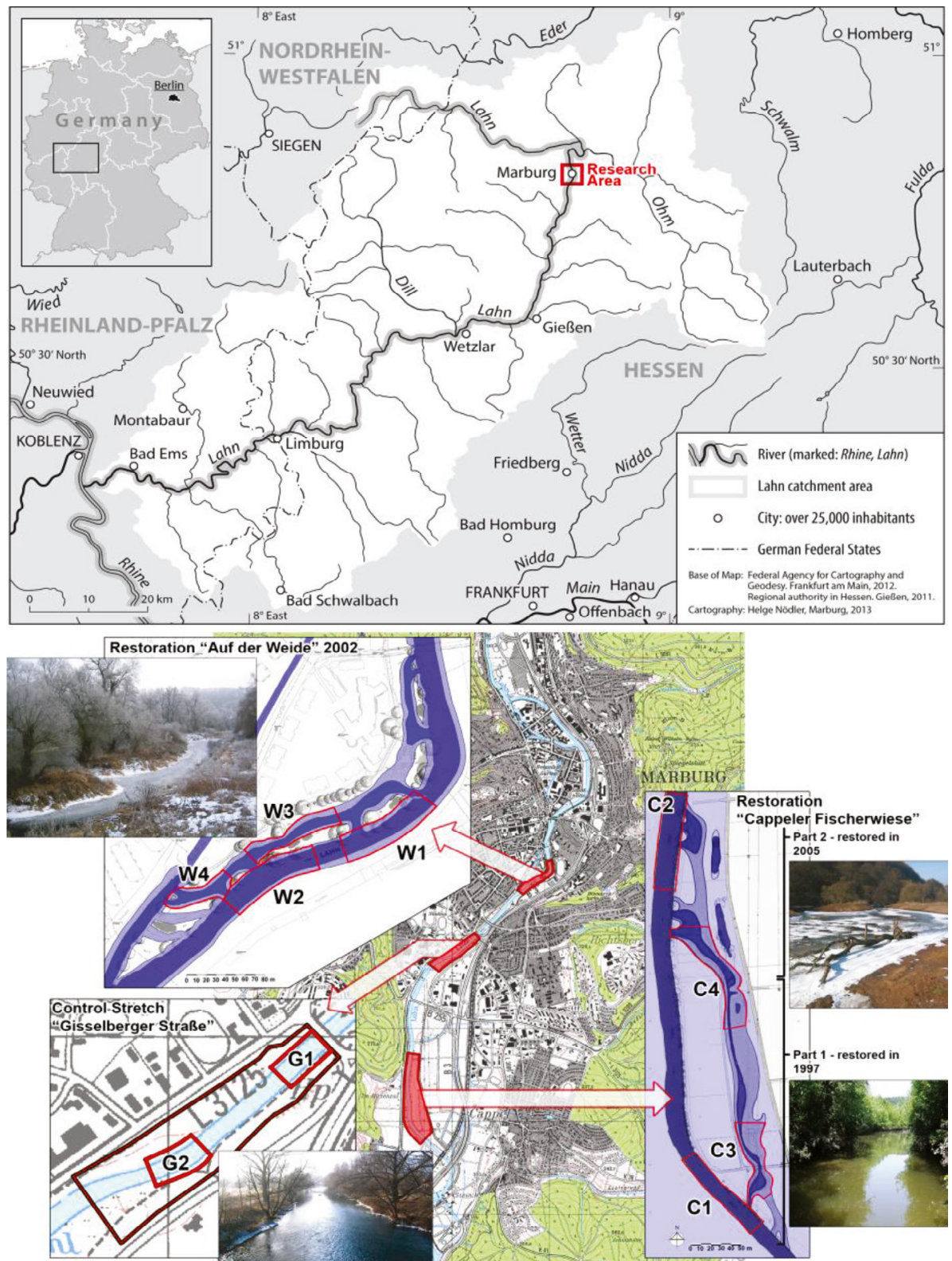

Figure 1: Location of the ten study sites within the three research areas and the Lahn catchment.

annually between 2006 and 2008 for a total of 3,207 data sets with 21 parameters each, resulting in the most detailed hydromorphological database for the analysed river stretches. Based on these morphological results a list of 32 microhabitat types was derived (see [17] for a detailed presentation of the TRiSHa method), which formed the basis for the biological sampling. Following the official WFD method for the assessment of the MZB (PERLODES 
[7, 18]), 165 biological samples (multi-habitat kick-sampling with a $500 \mu \mathrm{m}$ shovel sampler) were taken in the ten study sites over the course of the three years. Adjustments to the PERLODES method were implemented in so far as the highly generalized habitat assessment intended by PERLODES had been replaced by the much more detailed TRiSHa results, allowing for a far more accurate representation of the riverbed characteristics in the sample selection process. Furthermore each PERLODES subsample had been analysed individually (instead of a mixed sample for the whole research area), which allowed a detailed analysis of the relations between individual species and microhabitat conditions. All taxa were sorted on site and specimen copies were preserved in $70 \%$ alcohol and determined to the species level in the laboratory using a binocular microscope. The resulting taxa lists were imported into the ASTERICS software and the river type specific evaluation metrics were calculated [18].

\section{RESULTS AND DISCUSSION}

This results section discusses three parts of the study and presents some of the main results for each - the hydromorphological diversity as a result of the river restoration measures, the faunistic diversity based on the MZB sampling and the ecological quality assessment for the WFD.

\subsection{Hydromorphological diversity}

The results of the TRiSHa mapping are extensive and have previously been published in [15] and [17] and a detailed third paper has been submitted [19]. That is why only a brief hydromorphological characterization of the restored river stretches is presented here. The restoration measures have led to an increase of the morphological diversity. The total number of habitats recorded increased from 25 detected in the main channel to 32 when the side channels are included. There is also a significant difference $\left(\mathrm{p}<0.0001 ; \mathrm{Chi}^{2}=107.1\right)$ in the dominance structure of these habitat types in main and side channel sites. The main channel of the river is characterized by habitats dominated by rocks and gravel, while sand and clay habitats characterized the side channels (Fig. 2). These differences are even more pronounced when the spatial distribution of the different habitat types is considered. The main channel is

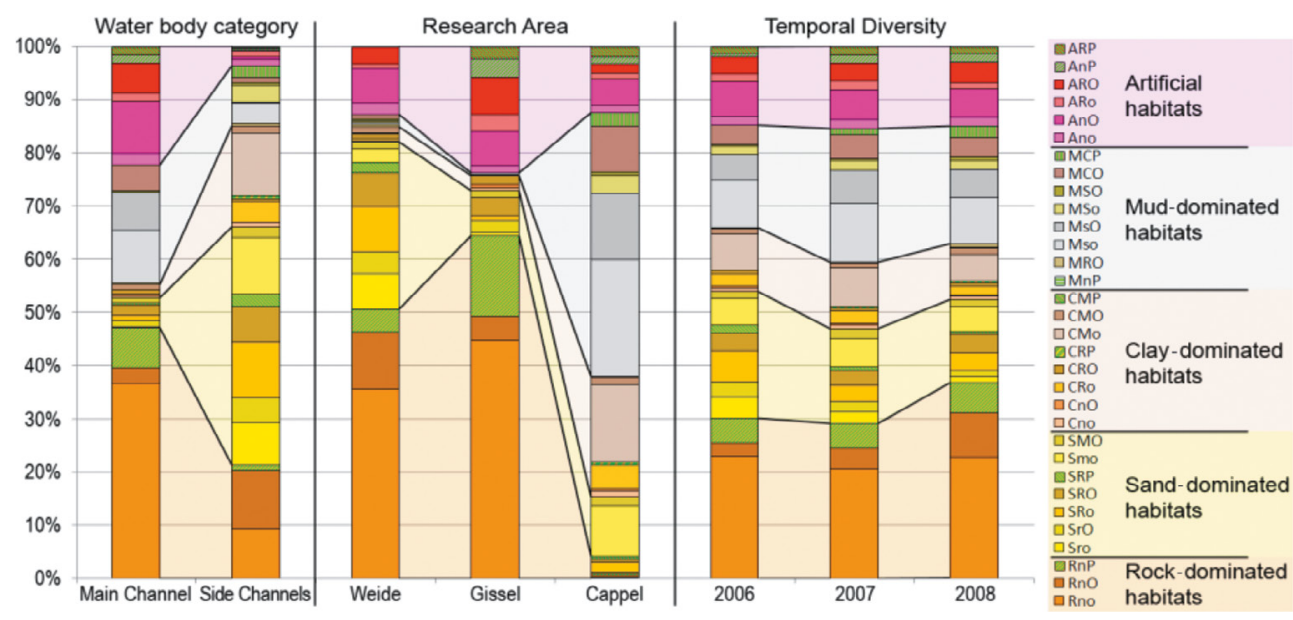

Figure 2: Spatial and temporal characteristics of the microhabitat distribution. 
characterized by a mostly homogeneous riverbed dominated (36.8\% in all main channel sites and up to $62.2 \%$ coverage in individual main channel sites) by just one habitat type (Rno Rocks and Gravel without organic matter) with most of other habitat types restricted to the riverbanks. The side channels, on the other hand, are characterized by a heterogenic habitat mosaic throughout the riverbed $([15,17,19])$ and the dominance of the most abundant habitat type is far less pronounced than in the main channel $(\mathrm{CMo}=11.9 \%, \mathrm{Smo}=10.7 \%$ and $\mathrm{SRo}=$ $10.6 \%$ for the three most frequently detected habitat types). There were also significant differences $\left(\mathrm{p}<0.0001, \mathrm{Chi}^{2}=142.1\right)$ detected between the free-flowing and the impounded river stretches (Fig. 2, where the research areas 'Weide' and 'Gissel' are free flowing while 'Cappel' is impounded). The reduced flow velocity in the impounded river stretch caused a strong shift towards mud-dominated habitat types. Similar results have been presented by Arscott et al. [20], Jähnig et al. [21] and Dewson et al. [22], although those studies did not focus on the micro scale of the choriotopes.

The temporal dynamic detected in the three research areas was also affected by the impoundment, resulting in a very high similarity of the impounded main channel sites from year to year $\left(\mathrm{p}=0.871 ; \mathrm{Chi}^{2}=8.3\right)$ and significant temporal changes in the free-flowing restored side channels $\left(\mathrm{p}=0.001 ; \mathrm{Chi}^{2}=51.2\right)$. Overall the restored river stretches showed a high flood-driven morphodynamic and especially the side channels were characterized by an ongoing change of their habitat composition so that the restoration measures have been very successful in creating a highly dynamic freshwater ecosystem. The high habitat diversity in river stretches with mixed flow conditions (like the main and side channel study sites analysed here) confirms the findings published by Raven et al. [23] and Lorenz et al. [24], who also could show an increase in the number of substrate and microhabitat types in re-meandering German lowland rivers with variable flow velocities. Rohde et al. [25] detected a heterogeneous mosaic pattern of the microhabitats in restored river stretches comparable to the structures presented here. Interestingly those mosaic structures were even more complex than in nearnatural reference sites. Jähnig et al. [26] analysed the riverbed structure of seven German mountain river sites (including the river Lahn) with restored multi-channel beds and could - in unison with the results presented here - show that the restoration led to a decrease of the dominance of the main substrate (from $75 \%$ in the single sites to $62 \%$ in the multi-channel sites).

\subsection{Faunistic diversity}

Based on the spatial distribution of the 32 microhabitat types 165 MZB samples were taken in the ten study sites. In order to study the relations between the riverbed morphology and the aquatic fauna and for the assessment of the spatial diversity of the MZB, the 165 taxa lists (one for each sample) were aggregated into 32 taxa lists - one for each habitat type. Two general metrics used of for the comparison of the different habitat types and groups are the animal abundance in individuals per $\mathrm{m}^{2}$ and the species richness as the number of taxa per habitat type (Fig. 3). The results vary greatly from habitat type to habitat type. The rock- and graveldominated habitat types were characterized by the highest species richness (up to 74 taxa in the type Rno and a total 85 taxa for the whole habitat group). This group is followed by the artificial habitats with up to 41 taxa for an individual habitat type (ARP - artificial habitats with rocks and macrophytes) and a total of 81 taxa for the whole habitat group. This high species diversity in the artificial habitats can be explained by the physical structure of the bank fixations found in the Lahn which emulate large rocks and an extensive interstitial, the natural habitat for a mountain river like the Lahn. The clay- and mud-dominated habitat groups, on the other hand, were characterized by a much smaller species richness (41 and 43 taxa) and with just ten taxa three clay and mud habitat types yielded the least species in this study (Fig. 3). 


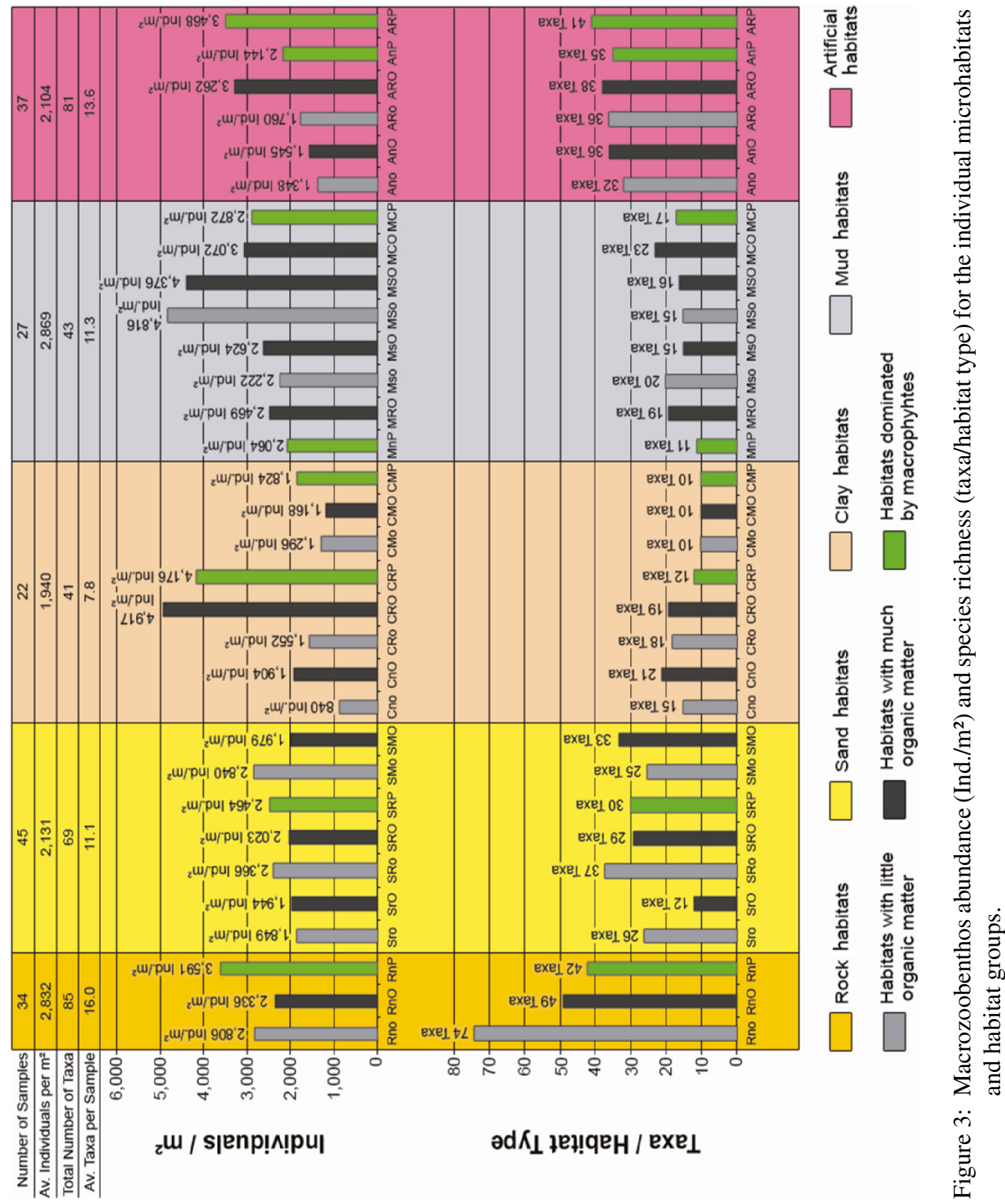


These results reflect that clay is a substrate that is difficult to colonize by the MZB as it mostly lacks the interstitial and structuring features as rocks or organic material while areas dominated by mud are characterized by extremely low oxygen concentration and even anoxic conditions. The Trichoptera, Diptera and Ephemeroptera provided the majority of the taxa, while the Diptera and Crustacea showed the highest population densities (with averages up to 1,112 Ind./m² for a single taxon) (Fig. 4). Only three taxa (Hydracarina sp., Tubificidae Gen. sp. and Gammarus roeseli) had been detected with a high consistency (found in more than $2 / 3$ of all samples) and a high population density ( $>200 \mathrm{Ind} . / \mathrm{m}^{2}$ ), while $91.6 \%$ of all taxa had been found in less than one-third of all samples and with densities of less than 50 Ind./ $\mathrm{m}^{2}$. The lower half of Fig. 4 exemplifies this specialization for the group of the mayflies (Ephemeroptera). Ephemera danica showed the highest abundances in sand-dominated habitats, where it could easily burrow itself into the fine sediments, while Serratella ignita was closely connected to habitat types characterized by macrophytes and Cloeon dipterum dominated the artificial habitats. This high level of specialization reflects the influence of a variety of abiotic parameters - from flow velocity to water depth, microhabitats, channel characteristics and even the research area.

A principal component analysis performed with the TRiSHa and MZB data sets revealed that the flow velocity, the microhabitats and the presence/absence of aquatic macrophytes are the most important environmental parameters responsible for the spatial distribution of the aquatic fauna while the water depth but also the differences between main and side channel were much less important (Fig. 5).

Cross-referencing this result with the autecological profiles of the MZB taxa confirmed the general accuracy of these results, even though the PCA explains only $32.48 \%$ of the detected variability. The PCA results were furthermore confirmed by an agglomerated hierarchical clustering (AHC) performed with the faunistic data sets. The nine clusters identified could be differentiated from each other by the flow velocity, the research areas (as a proxy for the effect of the impoundment), the macrophytes and the habitat groups (Fig. 6). These AHC results illustrate very well that each of the research areas has a unique MZB fauna and that the river restoration measures have had a positive effect on the overall species richness and biodiversity of the Lahn river.

\subsection{Ecological quality assessment}

The previous two subchapters have demonstrated that the river restoration measures have led to an increase of the faunistic diversity, which is a valuable goal in itself. But the question remained if this also led to an improved assessment of the research areas in regard to the WFD. In order to evaluate this, the habitat-specific taxa lists were aggregated into one list for each study area. The ecological quality was then calculated using the ASTERICS software. This evaluation is tailored to the different German river types by comparing the present state to reference conditions $[16,18]$. The core metrics for the assessment of the morphological integrity of the Lahn (stream type 9.2) are the German Fauna Index (tolerance metric), the percentage of metarhithral-taxa (functional metric), the percentage of EPT (Ephemeroptera, Plecoptera and Trichoptera) abundance classes (composition metric) and the number of EPTCBO (the EPT plus the Coleoptera, Bivalvia and Odonata) taxa (diversity metric). The results presented in Table 1 show that the overall ecological quality of the three study areas is only 'moderate' to 'unsatisfactory'. While the saprobic quality in all study areas reached a 'good' result (with index values between 1.98 and 2.15), the morphological degradation 


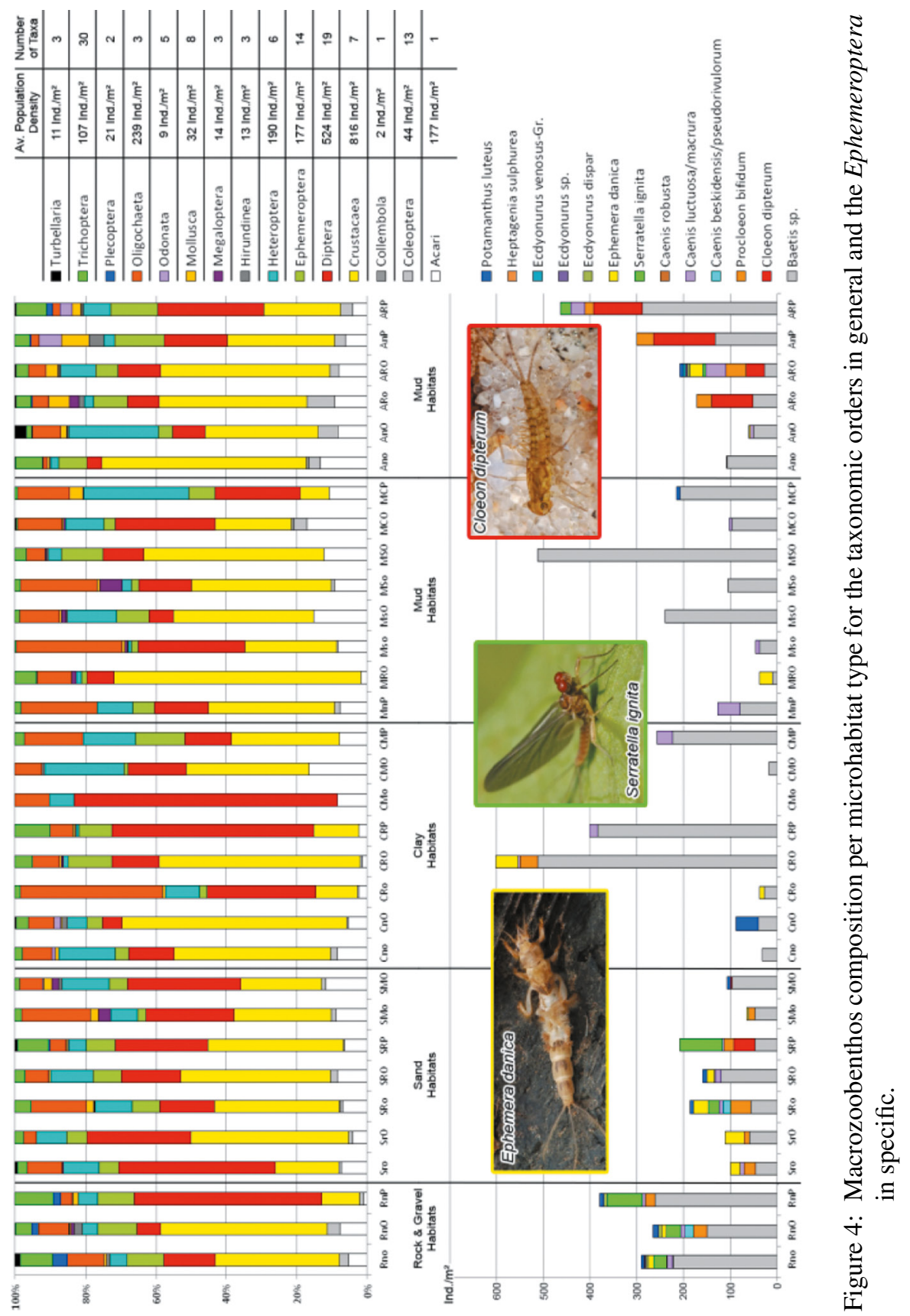




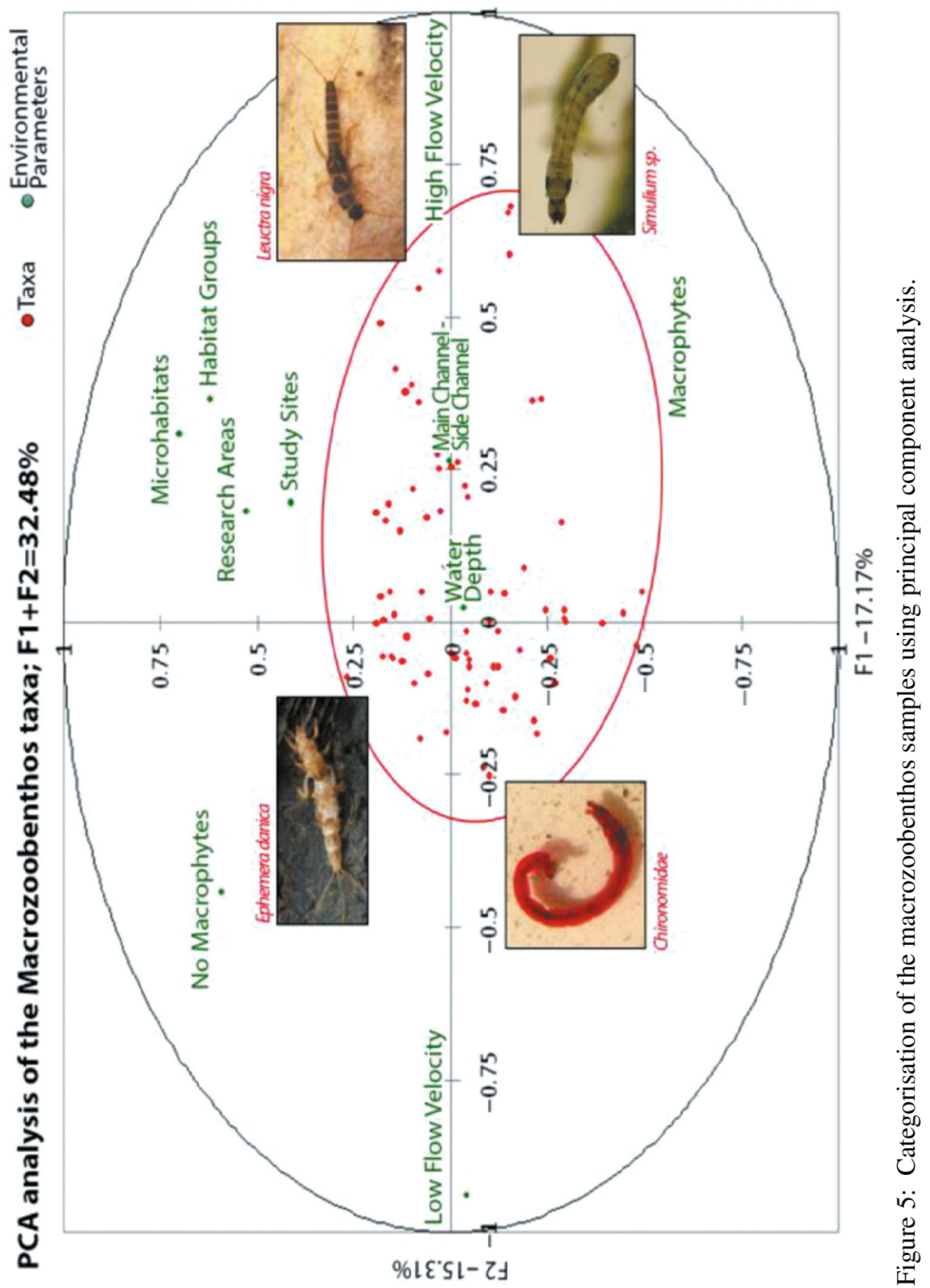




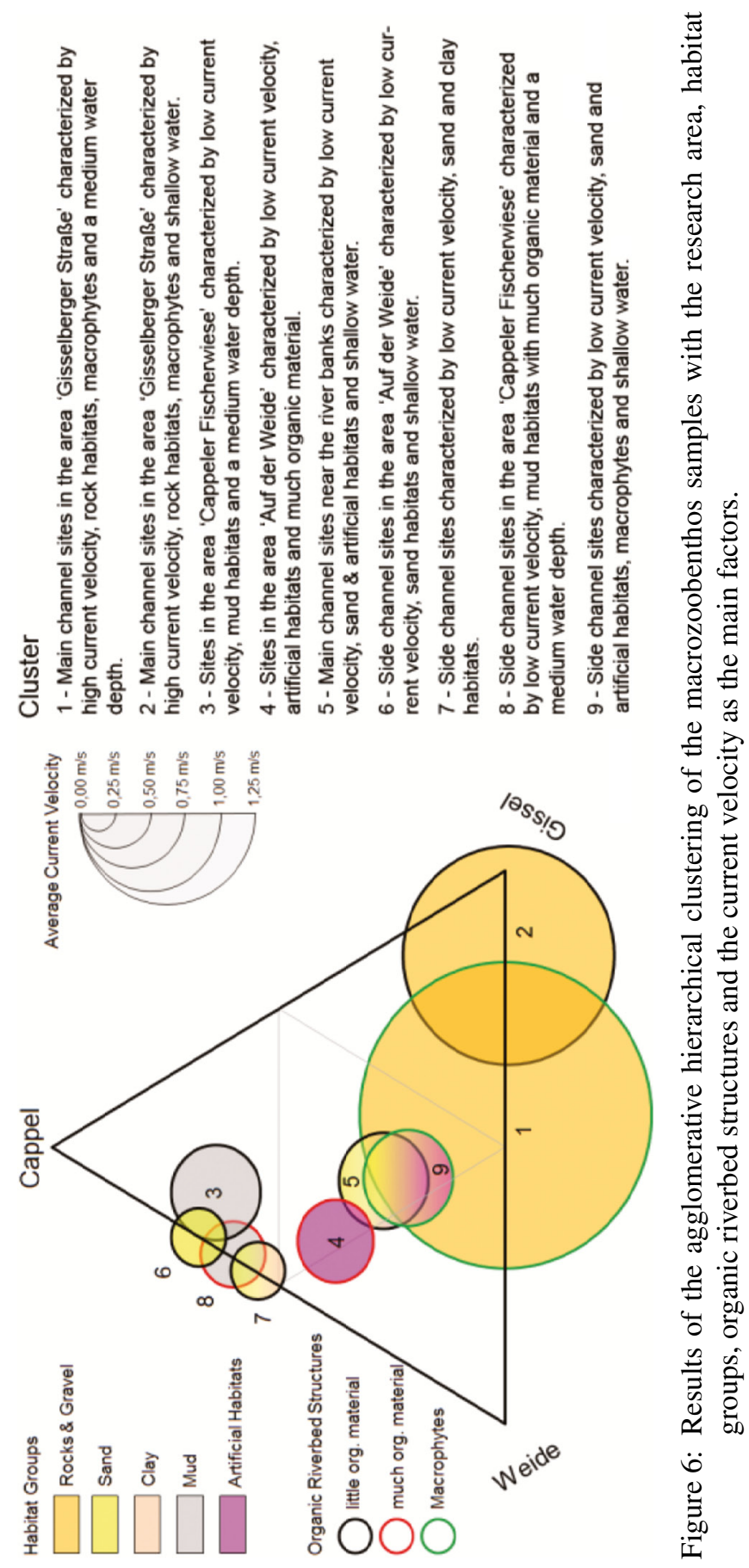


revealed the main deficits of the three areas. Of the four core metrics, only the diversity metric (the number of EPTCBO taxa) showed no degradation, meaning that the Lahn is characterized by a heterogeneous macroinvertebrate fauna which reflects the structural diversity of the riverbed and confirms the results presented earlier. The functional metric, on the other hand, was consistently rated as 'unsatisfactory'. The detected percentages ranged between $10.7 \%$ and $12.9 \%$, while the reference conditions for a type 9.2 river suggest that up to $25 \%$ of all taxa should be metarhithral taxa [16]. The low percentages in the study areas cannot be explained as direct consequences of the impoundment as even the free-flowing study areas showed severe deficits. But these results might well be the result of the high degree of impoundment in the Lahn river as a whole, which is a considerable obstacle for the migration of rheophilic taxa. The last two core metrics show a clear distinction between the free-flowing and the impounded study areas and thus are well suited for evaluating the impact of weirs on the ecological quality of the Lahn. The tolerance metric (German Fauna Index type 9.2) scored 0.55 ('moderate' quality) and 0.54 ('unsatisfactory' quality) in the free-flowing study areas, while the score in the impounded study area was only 0.23 ('bad' quality). Even more drastic are the differences between free-flowing and impounded areas for the composition metric (\% of EPT abundance classes). This core metric was rated 'good' in the free-flowing study areas ('Auf der Weide': 0.663 (44.9\%); 'Gisselberger Straße': $0.689(45.7 \%)$ ) which is close to the suggested reference conditions (55\% EPT abundance classes), while it was rated 'bad' in the impounded study area $(0.123(28.7 \%))$. In the impounded area, on the other hand, the result is close to the threshold for a complete degradation (25\%) [16].

Based on these results the ecological quality of the Lahn still shows deficits. Even worse, the restored areas have not been evaluated with higher scores than the unrestored control stretch. In order to analyse the influence of the restored side channels on the ecological quality in more detail, the taxa lists for the side and main channels were computed separately as well (Table 1). The results showed that there are indeed only very small differences between the main channel evaluation and the scores for the combined system. In the free-flowing study area 'Auf der Weide' the inclusion of the restored side channel study sites leads to a marginally improved saprobic index (2.02 to 1.98$)$ and to a slightly lower score for the morphological degradation ( 0.55 in comparison to 0.57 for the main channel alone). All the core metrics were also considerably lower in the side channel, but the overall assessment worsened for only the functional and tolerance metrics. In the impounded study area the saprobic index was also improved by the inclusion of the side channel study sites (2.2 to 2.15) while the morphological degradation remained unchanged. Three of the four core metrics showed worse scores in the side channel (with the diversity metric being the exception) which leads to lower scores for the functional and the composition metric. The composition metric for the combined system of main and side channel study sites was even rated 'bad', while the main channel itself had been rated only 'unsatisfactory'. The other two core metrics, however, showed slightly better scores for the combined system so that the overall score for the morphological degradation remained the same. The low scores for the restored side channels are surprising as they were characterized by a very high spatial diversity and temporal dynamic. Similar results, however, were provided by [16, 27-30] who could show that even a high habitat diversity and heterogeneity in restored river stretches did not have a major impact on the development of the benthic communities. Lorenz et al. [16] analysed restoration measures on the upper reaches of the Lahn and concluded that the sites need more time before developing high-quality MZB communities. The restoration measures analysed in the study presented here, however, were in part nine years old before the study began. Palmer et al. [30] conclude that restoration measures which focus solely on increasing the structural 


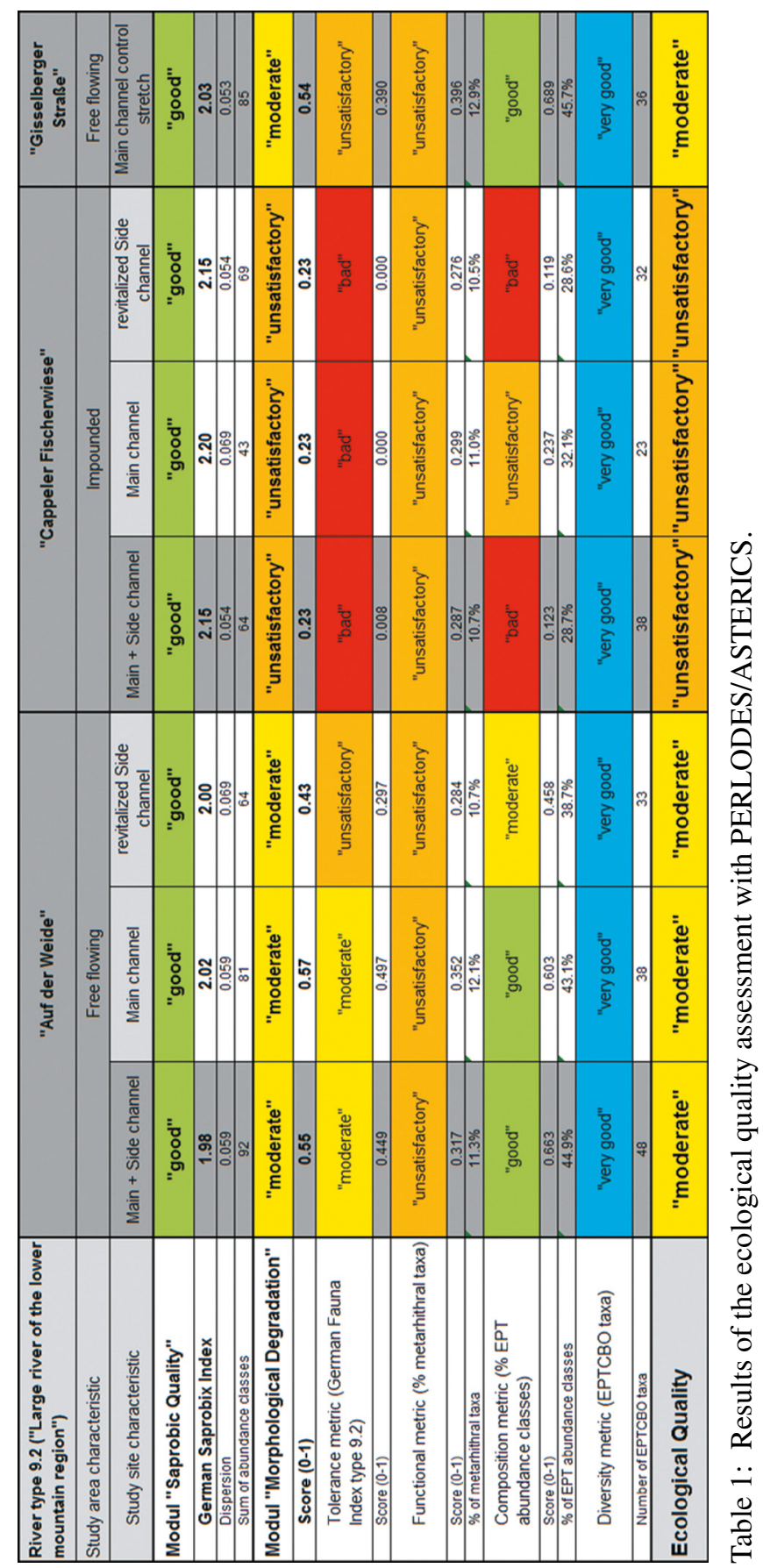


heterogeneity of the riverbed are bound to fail if larger-scale factors like the land use or - in the case of the Lahn - the impoundment - are not addressed as well. Another explanation for the lack of improvement of the ecological quality of the river despite the well-documented morphological diversity and dynamic can also be found in the reference conditions used for the assessment. The stream type 9.2 is characterized by a shallow riverbed dominated by rocks and gravel and a high flow velocity caused by a valley inclination of $3 \%$. These characteristics are valid for the upper reaches of the Lahn but not for the middle reaches analysed here which was also proven by the analysis of several historical maps of the Lahn catchment [15]. Downstream of the confluence of the rivers Lahn and Ohm, the Lahn valley has an inclination of only $0.76 \%$ and the riverbed is much deeper. Because of the reduced flow velocity, especially in the restored side channels, the typical coarse sediments are replaced by finer sediments which in turn result in a different MZB fauna [31, 32]. The taxa found in the side channels are indicators for lentic conditions - not because of an anthropogenic degradation but because of the natural landscape features of the Lahn.

\section{CONCLUSIONS}

The detailed analysis of the riverbed morphology revealed a high diversity and dynamic of the substrates and the aquatic microhabitats in the main and side channel sections of the river Lahn. The diversity was much larger in the restored side channels and the flow velocity turned out to be the most influential parameter for the recorded dynamic. This proves that the approach of the passive dynamic river restoration is well suited to create dynamic and valuable river ecosystems within the limited timeframe of the WFD. At the same time, the results have shown that the impoundment is an impairment that cannot be overcome with a passive dynamic approach. The faunistic assessment, however, does not reflect the detected high morphological diversity and quality. The restored research areas did not show any significant change of their ecological state. Possible reasons for this are catchment-wide effects of the river impoundment as well as the reference conditions used for the ecological assessment which are not adequate for the river Lahn downstream of the confluence with the Ohm. These results either question the value of a nationwide river typology with clearly defined and binding reference conditions or call for a modified or extended assessment tool for a reliable evaluation of rivers like the Lahn, which share characteristics with both mountain rivers and lowland streams and are heavily impaired by anthropogenic flow regulation.

\section{REFERENCES}

[1] Barbour, M.T., Gerritsen, J., Snyder, B.D. \& Stribling, J.B., Rapid Bioassessment Protocols for Use in Streams and Wadable Rivers - Periphyton, Benthic Macroinvertebrates, and Fish, 2nd ed., United States Environmental Protection Agency (US-EPA): Washington, DC, 344pp., 1999.

[2] Dickhaut, W., Fließgewässerrenaturierung Heute - Forschung zu Effizienz und Umsetzungspraxis - Abschlussbericht, Hamburg University of Applied Sciences: Hamburg, 120pp., 2005.

[3] BMU (ed.), Die Wasserrahmenrichtlinie - Ergebnisse der Bestandsaufnahme 2004 in Deutschland, Bundesministerium für Umwelt, Naturschutz und Reaktorsicherheit (BMU): Berlin, 67pp., 2005.

[4] HMULF (ed.), Gewässerstrukturgüte in Hessen 1999 - Erläuterungsbericht, Hessisches Ministerium für Umwelt, Landwirtschaft und Forsten (HMULF): Wiesbaden, 55pp., 2000. 
[5] European Commission (ed.), Directive 2000/60/EC of the European Parliament and of the Council of 23 October 2000 Establishing a Framework for Community Action in the Field of Water Policy (Water Framework Directive). OJ L 327, 22.12.2000, 93pp., 2000.

[6] Rolauffs, P., Hering, D., Sommerhäuser, M., Rödiger, S. \& Jähnig, S., Entwicklung eines Leitbildorientierten Saprobienindexes für die biologische Fließgewässerbewertung. UBATexte 11/2003, Umweltbundesamt: Berlin, 137pp., 2003.

[7] Sandin, L., Hering, D., Buffagni, A., Lorenz, A., Moog, O., Rolauffs, P. \& Stubauer, I., Experiences with different stream assessment methods and outlines of an integrated method for assessing streams using benthic macroinvertebrates. AQEM 3rd Deliverable, 87pp., available at http://www.eugris.info/displayresource.aspx?r=118, 2001.

[8] Schmedtje, U. \& Kohmann, F., Bewertung von Fließgewässern- Aussagekraft und Grenzen biologischer und chemischer Indizes. Wasser und Boden, 11, Blackwell Verlag: Berlin, pp. 610-612, 1988.

[9] Interwies, E., et al., Grundlagen für die Auswahl der kosteneffizientesten Maßnahmenkombinationen zur Aufnahme in das Maßnahmenprogramm nach Artikel 11 der Wasserrahmenrichtlinie - Handbuch. UBA-Texte 02/04, Umweltbundesamt: Berlin, 2004.

[10] Lepori, F., Palm, D., \& Malmqvist, B., Effects of stream restoration on ecosystem functioning: Detritus retentiveness and decomposition. Journal of Applied Ecology, 42, pp. 228-238, 2005. DOI: 10.1111/j.1365-2664.2004.00965.x.

[11] Bernhardt, E.S., et al., Synthesizing U.S. river restoration efforts. Science, 308, pp. 636-637, 2005. DOI: 10.1126/science.1109769.

[12] Koenzen, U., Erfolgskontrolle von Maßnahmen zur naturnahen Entwicklung von Fließgewässern - Hinweise für gezielte Maßnahmen zur Kompensation von Strukturdefiziten unter Berücksichtigung der Strahlwirkung. Schriftenreihe des DRL, 81, pp. 35-42, 2008.

[13] Moerke, A.H. \& Lamberti, G.A., Restoring stream ecosystems: Lessons from a Midwestern State. Restoration Ecology, 12(3), pp. 327-334, 2004. DOI: 10.1577/1548-8675(2002)022\&1t;0001:AROSRT\&gt;2.0.CO;2.

[14] Purcell, A.H., Friedrich, C. \& Resh, V.H., An assessment of a small urban stream restoration project in Northern California. Restoration Ecology, 10(4), pp. 685-694, 2002. DOI: 10.1577/1548-8446(1997)022\&lt;0012:AEPORA\&gt;2.0.CO;2

[15] Groll, M., Beziehungen zwischen der Gewässermorphologie und dem Makrozoobenthos an renaturierten Abschnitten der Lahn, Philipps-Universität Marburg: Marburg, 442pp., 2011.

[16] Döbbelt-Grüne, S., Hartmann, C., Zellmer, U., Reuvers, C., Zins, C. \& Koenzen, U., Hydromorphologische Steckbriefe der deutschen Fließgewässer-typen - Anhang 1 von Strategien zur Optimierung von Fließgewässer-Renaturierungsmaßnahmen und ihrer Erfolgskontrolle. UBA-Texte 43/2014, Umweltbundesamt: Dessau-Roßlau, 288pp., 2013.

[17] Groll, M., Thomas, A., Jungermann, L. \& Schäfer. K., Typology of Riverbed Structures and Habitats (TRiSHa) - A new method for a high resolution characterization of the spatial and temporal dynamic of freshwater ecosystems. Ecological Indicators, 61, pp. 219-233, 2016. DOI: 10.1016/j.ecolind.2015.09.019.

[18] Meier, C., et al., Methodisches Handbuch Fließgewässerbewertung - Handbuch zur Untersuchung und Bewertung von Fließgewässern auf der Basis des Makrozoobenthos vor dem Hintergrund der EG-Wasserrahmenrichtlinie, Universität Duisburg-Essen: Essen, 79pp., 2006. 
[19] Groll, M., The passive river restoration approach as an efficient tool to improve the hydromorphological diversity of rivers - Case study from two river restoration projects in the German lower mountain range. Geomorphology (accepted).

[20] Arscott, D.B., Tockner, K., van der Nat, D. \& Ward, J.V., Aquatic habitat dynamics along a Braided Alpine River ecosystem (Tagliamento River, Northeast Italy). Ecosystems, 5(8), pp. 802-814, 2002. DOI: 10.1007/s10021-002-0192-7.

[21] Jähnig, S.C., Lorenz, A.W., Lorenz, R.R.C. \& Kail, J., A comparison of habitat diversity and interannual habitat dynamics in actively and passively restored mountain rivers of Germany. Hydrobiologia, 712(1), pp. 89-104, 2013. DOI: 10.1007/s10750012-1264-0.

[22] Dewson, Z.S., James, A.B.W. \& Death, R.G., A review of the consequences of decreased flow for instream habitat and macroinvertebrates. Journal of the North American Benthological Society, 26(3), pp. 401-415, 2007. DOI: 10.1899/06-110.1.

[23] Raven, P.J., Holmes, N.T.H., Vaughan, I.P., Dawson, F.H. \& Scarlett, P., Benchmarking habitat quality: Observations using River Habitat Survey on near-natural streams and rivers in northern and western Europe. Aquatic Conservation Marine and Freshwater Ecosystems, 20, pp. 13-30, 2010. DOI: 10.1002/aqc.1103.

[24] Lorenz, A.W., Jähnig, S.C. \& Hering, D., Re-meandering German lowland streams: Qualitative and quantitative effects of restoration measures on hydromorphology and macroinvertebrates. Environmental Management, 44(4), pp. 745-754, 2009. DOI: 10.1007/s00267-009-9350-4.

[25] Rohde, S., Kienast, F. \& Bürgi, M., Assessing the restoration success of river widenings: A landscape approach. Environmental Management, 34(4), pp. 574-589, 2004. DOI: 10.1007/s00267-004-0158-y.

[26] Jähnig, S.C., Lorenz, A. \& Hering, D., Hydromorphological parameters indicating differences between single- and multiple-channel mountain rivers in Germany, in relation to their modification and recovery. Aquatic Conservation Marine and Freshwater Ecosystems, 18, pp. 1200-1216, 2008. DOI: 10.1002/aqc.875.

[27] Brooks, S.S., Palmer, M.A., Cardinale, C.M. \& Ribblett, S., Assessing stream ecosystem rehabilitation - Limitations of community structure data. Restoration Ecology, 10(1), pp. 156-168, 2002. DOI: 10.1126/science.289.5477.284.

[28] Jähnig, S.C., et al., A comparative analysis of restoration measures and their effects on hydromorphology and benthic invertebrates in 26 central and southern European rivers. Journal of Applied Ecology, 47, pp. 671-680, 2010. DOI: 10.1111/j.13652664.2010.01807.x.

[29] Kokes, J., River channel habitat diversity (RCHD) and macroinvertebrate community. Biologia, 66(2), pp. 328-334, 2011. DOI: 10.2478/s11756-011-0010-9.

[30] Palmer, M.A., Menninger, H.L. \& Bernhardt, E., River restoration, habitat heterogeneity and biodiversity - A failure of theory or practice? Freshwater Biology, 55, pp. 205-222, 2010. DOI: 10.1111/j.1365-2427.2009.02372.x.

[31] Brunke, M., Hoffmann, A. \& Pusch, M., Use of mesohabitat-specific relationships between flow velocity and river discharge to assess invertebrate minimum flow requirements. Regulated Rivers - Research \& Management, 17, pp. 667-676, 2001. DOI: 10.1002/rrr.626.

[32] Downes, B.J., Lake, P.S., Glaister, A. \& Bond, N.R., Effects of sand sedimentation on the macroinvertebrate fauna of lowland streams - Are the effects consistent? Freshwater Biology, 51, pp. 144-160, 2006. DOI: 10.1007/s002679900019. 